\title{
Design and Evaluation of Press Coated Formulation of Aceclofenac and Comparison with Marketed Preparations.
}

\author{
Mr. Jadhav S.B ${ }^{1}$, Dr. Kawtikwar P.S ${ }^{2}$., Dr. Wadher S.J ${ }^{3}$. \\ 1. School of Pharmacy Swami Ramanand Tirth Marathwada University, Nanded, \\ Maharashtra, India. \\ 2. S.N. Institute of Pharmacy, Pusad, Maharashtra, India. \\ 3. School of Pharmacy Swami Ramanand Tirth Marathwada University, Nanded, \\ Maharashtra, India.
}

\begin{abstract}
The primary objective of the studies is to investigate whether compression coating could be used to produce tablets providing maximum drug plasma concentration 6 to 8 hours after an evening dose taken at approximately 22:00. Fast Dispersible core tablets containing Aceclofenac were prepared using superdisintegrants like Ac-Di-Sol, Crospovidone and Sodium starch glycolate through wet granulation method and evaluated for various parameters. Prepared press coated tablets were characterized for physical parameters, drug content, lag time, in vitro drug release characteristics. Aceclofenac formulation tablets of batch F4 containing combination Methocel K4M and Methocel K100M showed desired lag time along with drug release as compare to other formulations. The Comparative dissolution study of optimized formulation containing Aceclofenac was carried with marketed preparations also showed good results.
\end{abstract}

Keywords: Press coated Tablets, lag time, Aceclofenac.

* Corresponding author: Mr. Jadhav S.B., School of Pharmacy Swami Ramanand Tirth

Marathwada University, Nanded, Maharashtra, India. Email: sbjadhav0777@gmail.com 


\section{Introduction}

The prepared press-coated tablets contained no drugs in the shell and the release of drug from internal core is presumed to commence, when the outer shell is removed by dissolution or erosion of the hydrophilic polymers on the core surfaces. Therefore, the desired lag time should be obtained which can be achieved by using different viscosity grade polymer and their combinations. Oral drug delivery is the most widely utilized route of administration among all the routes that have been explored for systemic delivery of drugs via pharmaceutical products of different dosage form. Oral route is considered most natural, uncomplicated, convenient and safe due to its ease of administration, patient acceptance and cost-effective manufacturing process [1].

The scientific studies of biological rhythms clearly reveal that biological functions and processes are not static over time. Rather, they are variable in a predictable manner as rhythms of defined period [2].

A Press coated drug delivery system is characterized by a lag time that is an interval of no drug release followed by rapid drug release. Press coated systems are basically timecontrolled drug delivery systems in which the system controls the lag time independently of environmental factors depending on polymer used [3].

NSAIDs are commonly used in these conditions to relieve pain and inflammation and to improve mobility, and are also used in the management of a variety of other painful conditions The treatment goals for osteoarthritis, rheumatoid arthritis and ankylosing spondylitis are generally similar, and are to stop or reduce joint inflammation and pain, maintain or improve functioning and mobility, minimize disability, and prevent, delay or correct deformity [4]

Aceclofenac is an inflammatory site specific NSAID, as inflammation drastically increases its activity. As such, it is highly efficacious at sites of inflammation, and at the same time, is well tolerated in the rest of the body [5]

\section{Materials and methods}

Aceclofenac was given by Concept Pharmaceutical Aurangabad, India. Microcrystalline cellulose (Avicel PH101), Ac-Di-Sol, Sodium Starch Glycolate, Crospovidone (Maple Biotech Pvt Limited, Pune) was used as components of the core tablets. The coating components were Hydroxy Propyl Methyl Cellulose (Methocel K4M, K15M and K100M) obtained from Colorcon Asia Pvt Limited Verna, Goa. All other ingredients and reagents were of analytical grade and were used as received.

\section{Result and Discussion}

\section{Identification by UV of Aceclofenac}

The $0.002 \% \mathrm{w} / \mathrm{v}$ solution of Aceclofenac was prepared in methanol and subjected for examination in the range of $220 \mathrm{~nm}$ to $370 \mathrm{~nm}$ on UV Spectrophotometer which showed highest absorption maxima at $274 \mathrm{~nm}$.

\section{Identification by FT-IR and DSC of Aceclofenac:}

FT-IR spectroscopy and DSC was carried out to check the compatibility between drug and excipients.

\section{Formulation of Press Coated Tablets}

The press-coating techniques have been applied for formulation of press coated tablets containing Aceclofenac in Core. Aceclofenac fast dispersible core tablets were prepared 
in seven formulations with varying concentration of three superdisintegrants: Croscarmellose Sodium (Ac-Di-Sol), Sodium starch glycolate and Crospovidone. MCC (Avicel) was used as diluents. Hydroxy Propyl Methyl Cellulose (Methocel K4M, K15M and $\mathrm{K} 100 \mathrm{M}$ ) used as coating agents.

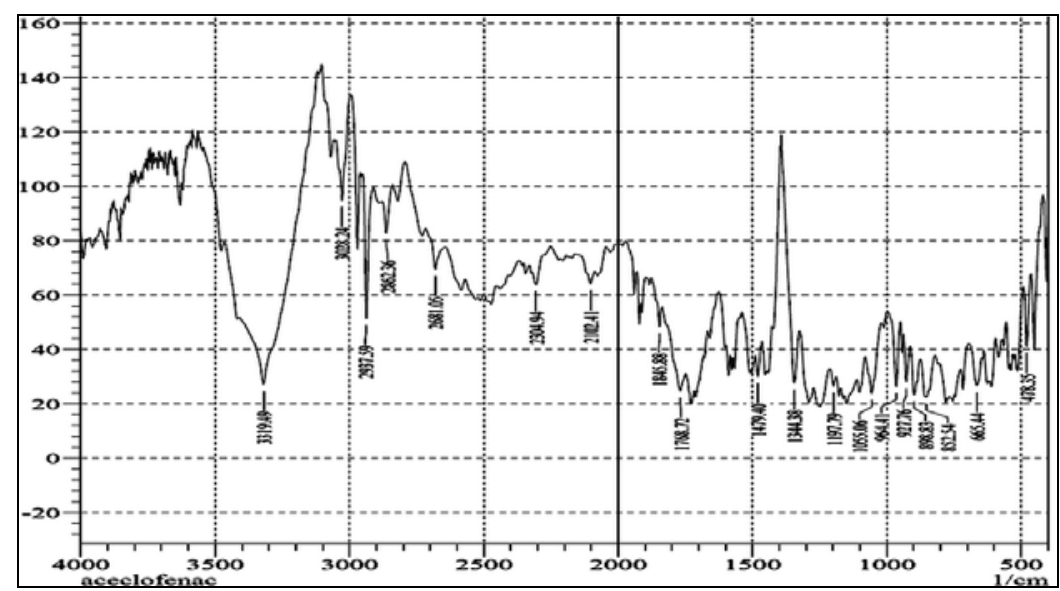

Figure No. 01: FTIR Spectra of Aceclofenac

All the characteristic peaks of Aceclofenac i.e. peaks for $\mathrm{N}-\mathrm{H}$ stretching vibration, $\mathrm{O}-\mathrm{H}$ stretching, $\mathrm{C}-\mathrm{H}$ stretching, $\mathrm{C}-\mathrm{N}$ stretching, $\mathrm{C}=\mathrm{O}$ stretching, $\mathrm{C}=\mathrm{C}$ stretching, $\mathrm{O}-\mathrm{H}$ in plane bending and Aromatic C-Cl stretching were present in the pure drug shown in Figure No. 01.

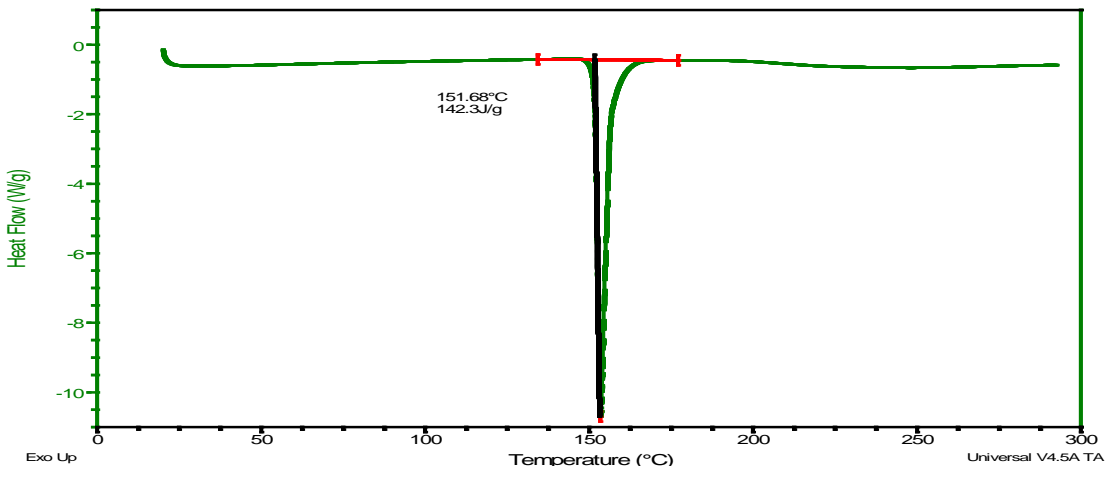

Figure No. 02: DSC Thermogram of Aceclofenac

The DSC Thermograms shows sharp endothermic peak at $151.68{ }^{0} \mathrm{C}$ corresponding to the melting point of Aceclofenac as shown in Figure No. 02.

\section{In-vitro Dissolution of core tablet and comparison with marketed preparation}

The percentage drug release of all the batches was found to be between $\mathbf{9 8 . 4 8}$ to $\mathbf{1 0 0 . 5 2}$ $\%$ this was within the acceptable limits. In vitro dissolution studies of the prepared fast dispersible core tablets containing Aceclofenac were performed in $\mathrm{pH} 6.8$ phosphate buffer using USP paddle apparatus Type -II. The tablets showed not less than $90 \%$ drug release in 20 minutes. Comparative dissolution profile of all Batches (A1 to A7) is given in Graph No.01. 


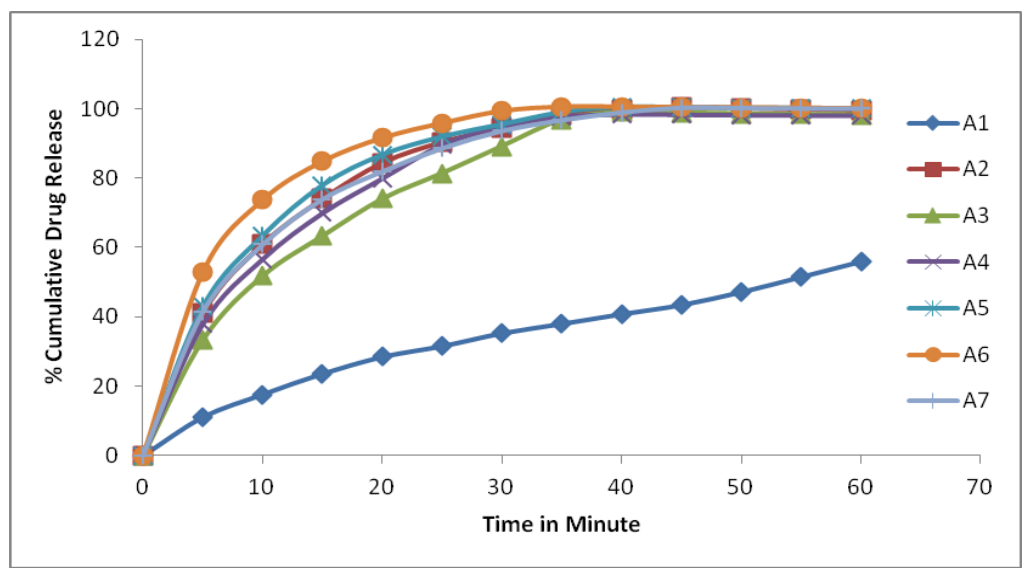

\section{Graph No. 01: In vitro drug release profile of all Batches (A1 to A7)}

The Comparative dissolution study of optimized A6 batch containing Aceclofenac was carried out with marketed fast dispersible tablet (FDT) of Aceclofenac 100mg and with Aceclofenac $100 \mathrm{mg}$ Conventional tablets (CT). The results of In vitro drug release study of optimized (A6) batch of Aceclofenac with marketed fast dispersible tablet (FDT) and Conventional tablets (CT) in pH 6.8 phosphate buffer were shown Graph No. 02.

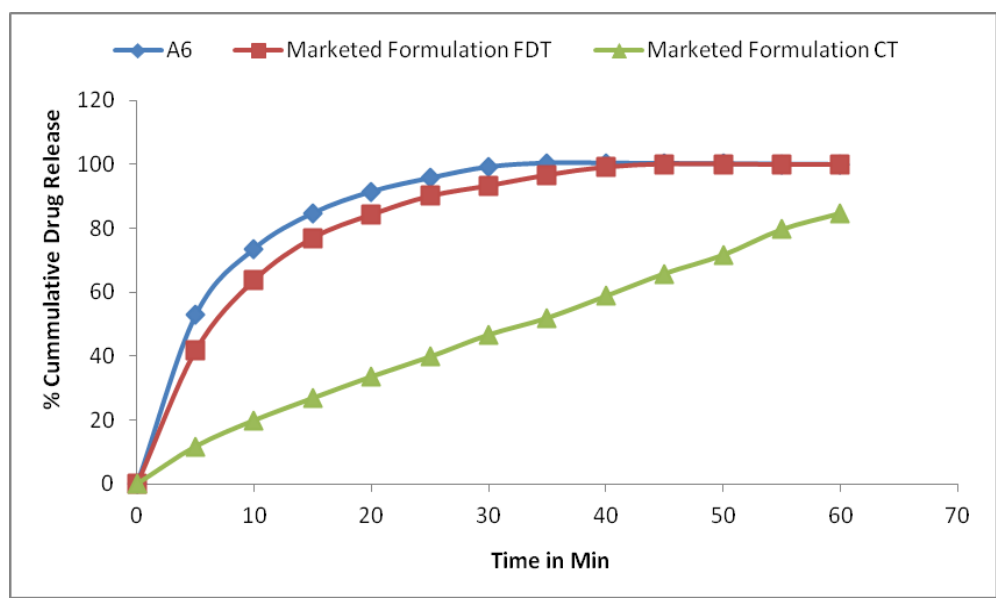

\section{Graph No. 02: In vitro drug release profile of optimized (A6) batch of Aceclofenac with marketed fast dispersible tablet (FDT) and Conventional tablets (CT)}

The marketed sample of fast dispersible tablet (Oace 100 FDT) containing Aceclofenac $100 \mathrm{mg}$ showed $93.333 \%$ of Aceclofenac release in 30 minutes and Aceclofenac $100 \mathrm{mg}$ Conventional tablets (CT) showed $46.691 \%$ of Aceclofenac release when tested in 900 $\mathrm{ml}$ of $\mathrm{pH} 6.8$ phosphate buffer Whereas optimized (A6) batch of Aceclofenac showed rapid release of $99.285 \%$ at 30 minutes as shown in Graph No.02.

\section{In-vitro Dissolution of press coated tablet and comparison with marketed preparation}

Dissolution profiles of the formulations F1 to F6 are shown in Graph No. 03.

Formulations F1 to F4 showed drug release after a predetermined off release period called as lag time; in both dissolution medium. The lag time was found in the range of 05 to 07 hours in different formulations, then after there was no release. The formulation F4 comparatively showed lag time (06 and 07 hours) in both dissolution media and 
considered as optimized formulation, so the same formulation's dissolution profile was studied in buffer $\mathrm{pH} 1.2$ for 02 hours followed by $\mathrm{pH} 6.8$ phosphate buffer solution for next 10 hours.

In case of formulation F4 showed a release in both the medium i.e. lags time of 06 and 07 hours in acidic and basic media respectively.

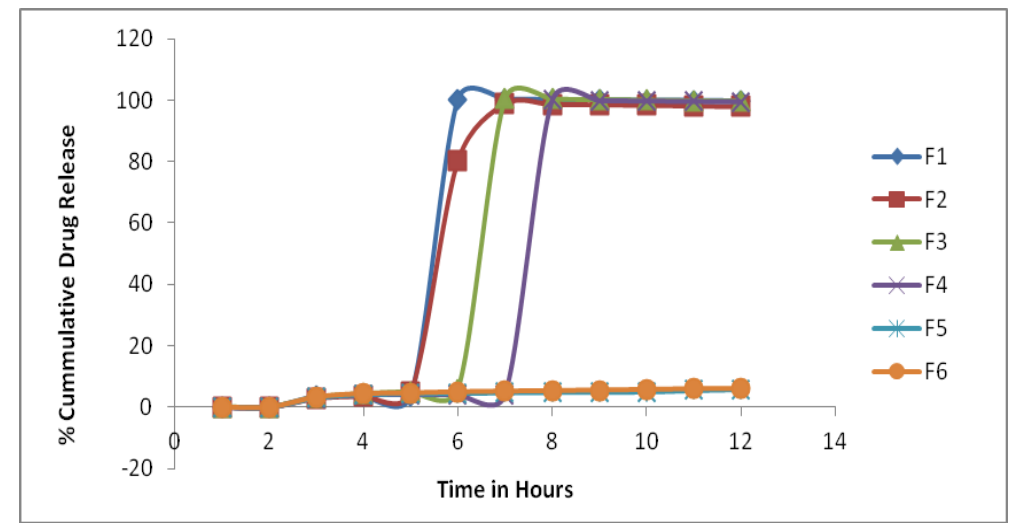

\section{Graph No. 03: In vitro drug release study of formulations F1 to F6 in Phosphate buffer pH 6.8}

The Comparative dissolution study of optimized F4 batch containing Aceclofenac was carried with marketed Aceclofenac SR tablets (Oace SR). The results of in vitro drug release study of optimized (F4) batch of Aceclofenac with marketed Aceclofenac SR tablets in $\mathrm{pH} 6.8$ phosphate buffer.

The marketed sample of Sustained release tablets containing Aceclofenac showed 70.377 $\%$ of Aceclofenac release after 07 hours when tested in $900 \mathrm{ml}$ of $\mathrm{pH} 6.8$ phosphate buffer whereas optimized (F4) batch of Aceclofenac showed drug release of $99.991 \%$ after 07 hours. (Graph No. 04)

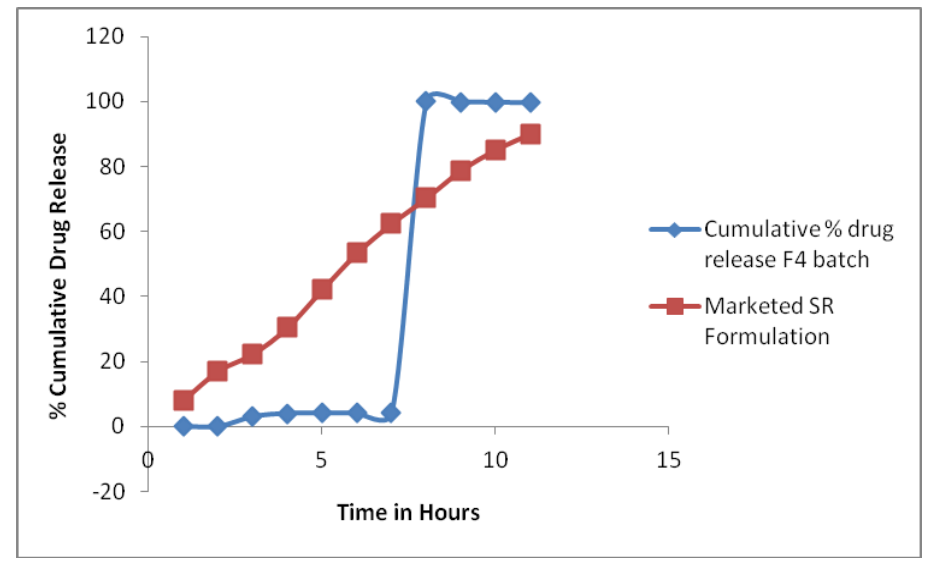

\section{Graph No. 04: In vitro drug release profile of optimized (F4) batch of Aceclofenac with marketed SR tablets}

\section{Summary and conclusion}

Overall, the results suggest that press coated tablets of Aceclofenac containing superdisintegrants in core (croscarmellose sodium, crospovidone and sodium starch glycolate) can be successfully formulated. It was observed that all formulations were acceptable with reasonable limits of standard required for press coated tablets. The study reveals that HPMC used as coating polymers were effective in different concentration. The Comparative dissolution study of optimized formulation containing Aceclofenac core 
and press coated tablets were carried with marketed preparations that showed better results.

\section{References}

1. Leon Lachman, Liberman H., "The theory and practice of Industrial Pharmacy", Special Indian Edition 2009, reprint 2010, CBS Publishers and Distributors Pvt. Ltd., New Delhi, (2010)296-302.

2. Smolensky $\mathrm{MH}$, Nicholas A, Peppas, Chronobiology drug delivery and Chronotherapeutics, Advanced Drug Delivery Reviews. (2007); 59:828-851.

3. Youan BC, Chronopharmaceutics: Gimmick or clinically relevant approach to drug delivery? Journal of Controlled release. (2004) Aug 27; 98(3):337-53.

4. Aher Kiran B, Girija B Bhavar, Hemant P Joshi, Sanjay R, Chaudhari, Recent advances in compression-coated tablets as a controlled drug delivery system, Saudi Pharmaceutical Journal. (2011).

5. British Pharmacopoeia Monographs: Medicinal and Pharmaceutical Substances, Aceclofenac, London, Vol-I and II. 2009; 1-4, 1973-1977.

6. Clausen AE, Bernkop-Schnurch A, Direct compressible polymethacrylic acid-starch compositions for site-specific drug delivery. Journal of Control Release. (2001) Jul 10; 75(1-2):93-102.

7. Efentakis M, Koligliati S, Vlachou M, "Design and evaluation of a dry coated drug delivery system with an impermeable cup, swellable top layer and pulsatile release”, International Journal of Pharmaceutics. (2006) Mar 27; 311(1-2):14756.

8. Fukui E, Uemura K, Kobayashi M, Studies on applicability of press coated tablets using hydroxy propyl cellulose (HPC) in the outer shell for timed-release preparations. Journal of controlled release. (2000) Aug 10; 68(2):215-23.

9. Garala KC, Ekshinge VB, Jarag RJ, Shinde AJ, Fast-disintegrating Aceclofenac tablets: formulation development using simplex lattice design, Thai Journal of Pharmaceutical Sciences. (2008); 32: 77-81.

10. Lin SY, Kawashima Y, "Review-current status and approaches to developing presscoated Chrono-delivery as a controlled drug delivery system", Journal of controlled release. (2012) Feb 10; 157(3):331-53.

11. Sangalli ME, Maroni A, Zema L, Busetti C, Giordano F, Gazzaniga A, In vitro and in vivo evaluation of an oral system for time and/or site-specific drug delivery. Journal of Controlled Release. (2001) May 18; 73(1):103-110.

12. McConville JT, Ross AC, Chambers AR, Smith G, Florence AJ, Stevens HN, The effect of wet granulation on the erosion behaviors of an HPMC-lactose tablet, used as a rate-controlling component in a pulsatile drug delivery capsule formulation, European Journal of Pharmaceutics and Biopharmaceutics. (2004) May 1; 57(3):541-549.

13. Rani Sonika, Seth Nimrata, Rajnibala, Banerji Angshu, "Pulsatile Drug Delivery System: Methods and Recent Trends" International Journal of Recent Advances in Pharmaceutical Research. (2015); 5(3): 250-259.

14. Sadaphal KP, Thakare VM, Gandhi BR, Tekade BW, "Formulation and evaluation of pulsatile drug delivery system for chronobiological disorder: asthma" International Journal of Drug Delivery System. (2011) Apr 1; 3(2):348-356.

15. Sangalli ME, Maroni A, Foppoli A, Zema L, Giordano F, Gazzaniga A, Different HPMC viscosity grades as coating agents for an oral time and/or site-controlled delivery system: a study on process parameters and in vitro performances. European Journal of Pharmaceutical Sciences. (2004) Aug 1; 22(5):469-476.

16. Toyohiro Sawada, Hiromu Kondo, Hiroshi Nakashima, Kazuhiro Sako, Masahiro Hayashi; "Time-release compression coated core tablet containing Nifedipine for chronopharmacotherapy", International Journal of Pharmaceutics. (2004) Aug 6; 280(1-2):103-11. 
17. Zade PS, Kawtikwar PS, Sakarkar DM, Formulation evaluation and optimization of fast dissolving tablet containing Tizanidine hydrochloride, International Journal of Pharma Tech Research. (2009) Jan; 1(1):34-42.

18. Zilpe C, Dhumale A, Gudalwar B, Kawtikwar PS, Sakarkar DM, Development and evaluation of pulsatile press coated tablet to control early morning BP surge. International Journal of Pharma World Research. (2012); 3(2), 5. 